\title{
Assessment of Students' Conceptual Knowledge in Limit of Functions
}

\author{
Ashebir Sidelil Sebsibe ${ }^{1 *}$, Nosisi Nellie Feza ${ }^{2}$ \\ ${ }^{1}$ Wachem University, Department of Mathematics, Hossana, ETHIOPIA \\ ${ }^{2}$ Central University of Technology, Faculty of Humanities, Free State (CUT), Private Bag X20539, Bloemfontein, 9300, SOUTH \\ AFRICA \\ *CORRESPONDENCE: $\square$ ashebir145@gmail.com
}

\begin{abstract}
Conceptual understanding of calculus is crucial in the fields of applied sciences, business, and engineering and technology subjects. However, the current status indicates that students possess only procedural knowledge developed from rote learning of procedures in calculus without insight of core ideas. Hence, this paper aims to assess students' challenges and to get insight on common barriers towards attaining conceptual knowledge of calculus. A purposive sample of 238 grade 12 natural sciences students from four different schools in one administrative Zone of Ethiopia were selected to participate in this study. An open ended test about limit of functions at a point and at infinity was administered and analyzed quantitatively and qualitatively. The findings reveal a number of factors about students' knowledge such as: lack of conceptual knowledge in limit of functions, knowledge characterized by a static view of dynamic processes, over generalization, inconsistent cognitive structure, over dependence on procedural learning, lack of coherent and flexibility of reasoning, lack of procedural fluency and wrong interpretation of symbolic notations. Students' thinking strategies influencing these challenges originate from their arithmetic thinking rather than algebraic, linguistic ambiguities, compartmentalized learning, dependence on concept image than concept definition, focus in obtaining correct answers for wrong reasons, and attention given to lower level cognitive demanding exercises.
\end{abstract}

Keywords: Calculus, difficulty, error, function, infinity, limit

\section{INTRODUCTION}

Students' success in their engineering, sciences and technology programs in higher education depends highly on conceptual knowledge of calculus. Hence, calculus becomes a pre-requisite for most sciences, technology and engineering fields in the undergraduate programs. Nurturing conceptual knowledge of calculus is a vital way to give rise to the scarce numbers of future scientists, technologists, mathematicians and engineers (Carlson \& Oehrtman, 2005; Roble, 2017; Sadler \& Sonnert, 2016).

While calculus is a gateway to advanced science and mathematics (Roble, 2017; Sadler \& Sonnert, 2016), limit is a gateway to calculus (Zollman, 2014). Although derivatives and integrals makeup the majority of calculus, sound understanding of limit is necessary to learn these major concepts in calculus (Maharaj, 2010; Muzangwa \& Chifamba, 2012; Rabadi, 2015). According to Salas, Hille, and Etgen (2007, p.53) "without limit, calculus does not exist; every single notion of calculus is a limit in one sense or another". Thus, limited knowledge of limit becomes a disadvantage when dealing with the subsequent concepts such as convergence, continuity, derivative and integral (Juter, 2006). Economies today struggle to provide relevant human capital

Article History: Received 7 August $2019 \bullet$ Revised 4 November $2019 \bullet$ Accepted 4 November 2019

(C) 2020 by the authors; licensee Modestum Ltd., UK. Open Access terms of the Creative Commons Attribution 4.0 International License (http://creativecommons.org/licenses/by/4.0/) apply. The license permits unrestricted use, distribution, and reproduction in any medium, on the condition that users give exact credit to the original author(s) and the source, provide a link to the Creative Commons license, and indicate if they made any changes. 
that are innovative, critical and advance in thinking. Developing scientists with higher knowledge levels will contribute to the fourth industrial revolution and advance science.

Regardless of the comparative importance of calculus, researchers in different contexts have shown that students have problems in gaining accurate understanding of the limit concept in particular and calculus concepts in general (for instance, Çetin, 2009; Jordaan, 2005; Juter, 2006; Moru, 2006; Muzangwa \& Chifamba, 2012). The classroom teaching is still dominated by rules and procedures. As a result of this practice, most of the students perform rules and procedures without internalizing and focusing on the embedded concepts (Berry \& Nyman, 2003; Bezuidenhout, 2001).

In addition to the above observations, good marks obtained by students in teachers made tests and classroom evaluations do not translate to the required conceptual knowledge in calculus. Researchers (for items designed to diagnose systematic errors) find evidence of students' difficulties and lack of knowledge in calculus. Thus, while students' performance on teachers made test and examination papers demonstrate some evidence of learning and understanding, researchers' findings confirm misconceptions, rote learning and lack of conceptual knowledge (Idris, 2009). This gap is more visible to teachers of non-mathematics courses in which mathematics is the pre-requisite for the course that they teach (Bezuidenhout, 2001; Idris, 2009). The extent in which teachers and researchers are aware, identify and react to students' difficulties is very important for scientific growth. Accordingly, the demands of alternative approaches to overcome these challenges specifically in the areas where access to educational technology is not at the desired level are compulsory. As Ethiopia is part of the world, the case is not different. In addition, in every discipline, concepts are a starting point to promote learning and progress in a given subject. This mainly is true of mathematics for it is very much sequential by its character. The understanding of succeeding concepts is possible if only pre-requisite concepts are well recognized.

Experiences and public evidence disclose that difficulties in calculus brought from grade 12 inhibit students' progress at university. The literature noted that those difficulties are due to teaching-learning practices that focus to a great level to the procedural part neglecting the solid foundation that underpins concepts (Aspinwall \& Miller, 2001). Thus, the issue demands exploration of other alternative strategies to approach calculus so that students gain better conceptual knowledge. The researchers argue that observed difficulties could provide valuable learning opportunities for students learning, provided they appropriately utilized. Therefore, it is important to asses and design preventive strategies to overcome observed difficulties and improve students' level of conceptual knowledge. This paper is part of consequent studies aimed to design learning models that are supposed to improve students understanding of calculus concepts. However, this paper only reports the explored students' difficulties that they demonstrate in coming to understand limit of functions.

In line with this paper's objective, the study addresses the following two specific research questions: 1) what are the challenges that students encounter in coming to understand limit of functions? 2) what are the common conceptual issues and approaches that cause students' difficulties in calculus?

\section{THEORETICAL FRAMEWORK}

The theoretical framework of this study is Action, Process, Object, and Schema (APOS). APOS is a constructivist framework of learning developed based on Piaget's reflective abstraction. The notion of reflective abstraction focuses on actions or operations done by students on physical or mental objects. That is, reflective abstraction is set of mental operations that are directly invisible but be inferred from prolonged observations or qualitative actions of students (Dubinsky, 2002; Glasersfeld, 1995).

Reflective abstraction has three components: (i) expansion of existing mental structure (ii) reconstruction of existing mental structures and (iii) a process of resolving contradictions in one's mental structure (Pritchard \& Woollard, 2010). Therefore, reflective abstraction is a progression through construction. And Dubinsky (2002) identified five types of constructions in reflective abstraction. These are interiorization, coordination, encapsulation, generalization, and reversal. Dubinsky in co-operation with other researchers in Research in Undergraduate Mathematics Education Community (RMEC) used these five constructs to describe how process and object level conception are constructed and formulate APOS theory.

According to Asiala et al. (1997, p. 9), formation of a mathematical knowledge "initiates through exploitation of existing mental objects to form actions; actions are then interiorized to form processes which 
are then encapsulated to form objects". The whole cognitive configuration is said to be a schema. The descriptions of action, process, object and schema are discussed below.

Action- is explained like "a repeatable mental or physical manipulation of objects" (Moru, 2006, p. 49). In this stage, the conversion of objects is thought of as exterior, and the student is only conscious about executing routine procedures (Dubinsky \& McDonald, 2001). It is like assembling equipment using a manual or according to Moru (2006) the ability to pick a number for a variable and compute value of an algebraic expression. For instance, in learning limit of a function for a student at action level $\lim _{x \rightarrow a} f(x)=f(a)$ (Cottrill et al., 1996) can be best example for the above explanation. Although action level conception is limited, it can serve as base line of the concept formation process. For instance, to introduce limit dynamically one can use sequence of actions (i.e. evaluating $f$ at a sufficient amount of points both from the right and the left close to $a$ ) so that students can predict the result.

Process- when a student is aware about the actions she/he is performing, the actions then are interiorized to a process (Cottrill et al., 1996). Thus, the process stage is relatively internal and involves visualizing a conversion of mental or physical objects without actually computing but by deduction. In this stage, students can carry out the same action without external stimuli (without a manual, a guide or a teacher). Students in this stage can also have a mental representation of a process, turn around the process as well as use it with other processes. Coordination is the creation of a process by bringing together two or more processes (Cotrill et al., 1996).

Computation of limit involves coordination of the input process and the corresponding output through the given function (Cotrill et al., 1996). Thus, a student at process level can evaluate (say $\lim _{x \rightarrow 0^{+}} \frac{1}{x}=\infty$ ) without consideration of specific values at a time or with computing the first few elements and contemplating the remaining. The essential difference between an action and a process is that in action, it is external and students need step by step direction to carry out the transformation whereas in the process level, the transformation carried out is internal and conceived in terms of relationships between one's cognitive structures (Carlson \& Oehrtman, 2005). For instance, for the items

- $\lim _{x \rightarrow 0}\left(x^{3}+2 x\right)=$

- If $f(x)=\left\{\begin{array}{l}x+2 \text { if } x \leq 3 \\ 6-x \text { if } x>3\end{array}\right.$ then $\lim _{x \rightarrow 3} f(x)=$

A student at action level conception of limit of function at a point can answer the first but not the second. She/he possibly answers the second as either 5 or 3 . But one at a process level may answer both correctly.

Object- an object level concept formation is a level where a student perceives the concept as something to which actions and processes may be performed. A student in this stage conceives the totality of the process as a whole and understands that conversions can be performed on it (Cottrill et al., 1996). Encapsulation is the construction of a cognitive object through awareness of totality of a process by imagination and manipulation of it as a whole without performing subsequent actions (ibid). A student who encapsulated a process in to object level of limit as in the above example for instance, have object view of the limit value so can act on it. Thus, given $\lim _{x \rightarrow a} f(x)$ and $\lim _{x \rightarrow a} g(x)$ then she/he can easily compute $\lim _{x \rightarrow a}[f(x)+g(x)]$.

Schema- is described as the whole conceptual structure which is result of consistent compilation of actions, processes, and objects (Cottrill et al., 1996). Since this schema level is compilation of the preceding levels, a student at this level is competent enough to flexibly move back and forth among all levels. Generalization is the ability to extend the acquired schema to a higher level of phenomenon (Dubinsky, 2002). Reversal, on the other hand, is the ability to think of an existing mental structure in reverse to extend it or construct a new mental process. For instance, in calculus, pairs of processes that are reversal are differentiation and integration. These basic constructs, the piece of knowledge that can be constructed in coming to learn a concept and the interplay among them is presented in Figure 1 taken from Dubinsky (2002, p. 107).

Due to the constructive nature of concept formation, students make a mental representation about a concept in coming to understand the concept. As students got more experience about the concept, such mental representation may be modified or other type of representation may be formed. The term "concept image" stands for all the mental pictures, together with a set of properties which are associated with an individual's mind to a given concept (Tall \& Vinner, 1981). On the other hand, concept definition refers to the words specifying the concept as defined by the scientific community in a given discipline (Tall \& Vinner, 1981). 


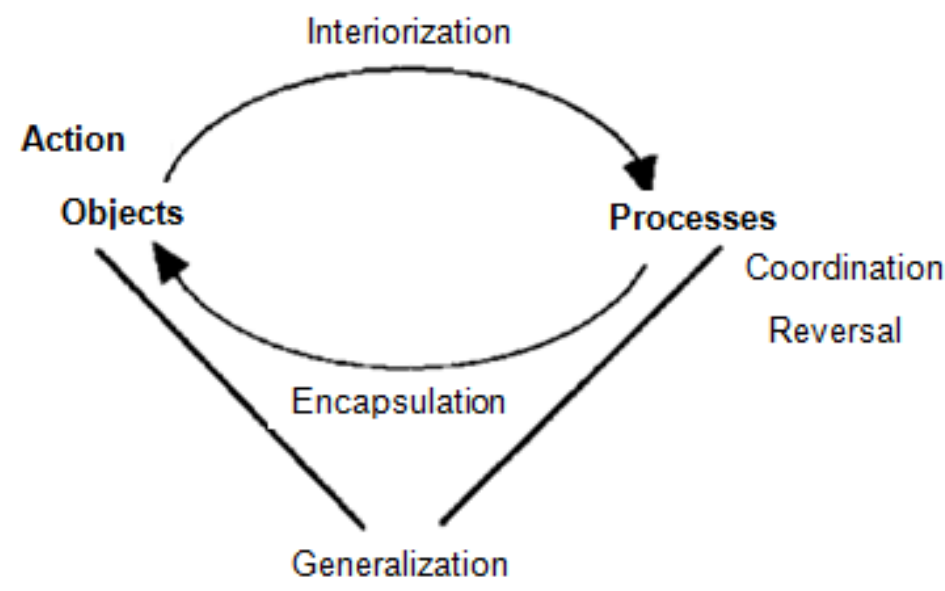

Figure 1. Constructs of mathematical knowledge and their interplay

A concept image then can be correct, partially correct, or incorrect (with respect to the concept definition), and it is dynamic in that students can alter it as a function of maturity and experience with the concept. Such concept image consists of all representations from experiences linked to the concept of which there may be several sets of representations constructed in different contexts. These representations possibly merge as the individual becomes more mathematically mature. Otherwise, multiple representations of the same concept can exist in multiple forms if the individual is unconscious of the fact that they represent the same concept. Tall and Vinner (1981) use the term "evoked concept image" to describe existence of inconsistent concept image by saying in different contexts the same concept name may evoke different concept images. Thus, if a student has matured and stable concept image she/he can demonstrate consistency and flexibility during problem solving.

An individual's concept images about a certain concept may match or differ from the formal concept definition taught. If they do not match, the individual face an obstacle in solving problems involving the given concept or hinder her/his further knowledge formation. As learners encounter mismatch of their current knowledge (concept image) and what teachers or books say (formal concept definition), they develop frustration, which position them in a cognitive conflict. This being in a state of trouble (mental disequilibrium), can be detected by students' response to test items or class activities. If students derived to explore the trouble systematically and carefully in order to reconcile and settle their disturbed state successfully, results in learning otherwise, can be a causes of dissatisfaction or dropout (Pritchard \& Woollard, 2010).

The state of being in disequilibrium and the effort exerted to come out of it is particularly important to develop deep understanding of a concept. Usually, lack of conceptual understanding is revealed by inappropriate, alternative or incomplete concept image. Many researchers (e.g. Makonye, 2012) describe this alternative concept image by the term "misconception". Careful analysis of students' reaction to specially designed tasks (qualitative written response, interview or observation) can help to predict about their cognitive structure (conception or misconception). Because of this, the concept image and concept definition construct preferred by several researchers to study difficulties in mathematics. Concept image as defined by Tall and Vinner substitutes schema in APOS framework of error analysis (Stewart, 2008, p.26). In this study the term concept image is used instead of schema and it refers to an inner model of reality constructed by learners as a result of experience with a particular concept.

\section{METHOD AND MATERIAL \\ Description of Participants}

This study was conducted in one administrative zone ${ }^{1}$ of a regional state in Ethiopia. Grade 12 natural science stream students in the Zone constituted population of the study. With a purposive sampling approach, four schools and four intact classroom students' one from each school were selected based on schools' voluntariness to provide access for the study, teachers' voluntariness to allow the students and students'

${ }_{1}^{1}$ The third top to down administrative level of the government structure 
Table 1. Interpretation of distracters in item 1

\begin{tabular}{ll}
\hline Which one of the following is true? & Interpretation (concept image) \\
$\begin{array}{l}\text { A. limit is a number beyond which a function cannot attain } \\
\text { values }\end{array}$ & limit is a boundary \\
\hline $\begin{array}{l}\text { B. limit is a number that the function value approaches but } \\
\text { never reaches }\end{array}$ & $\begin{array}{l}\text { limit is unreachable (and hence, not a } \\
\text { static object) }\end{array}$ \\
\hline $\begin{array}{l}\text { C. limit is an approximation that can be made as accurate as } \\
\text { you wish }\end{array}$ & $\begin{array}{l}\text { limit is an approximation (and hence a } \\
\text { process) }\end{array}$ \\
\hline D. limit of a function is value of the function at the limit point & limit is a substitution \\
\hline $\begin{array}{l}\text { E. none of these is true } \\
\text { Explain why ... }\end{array}$ & $\begin{array}{l}\text { Good conception. but has to be evaluated } \\
\text { based on the explanation she/he provided }\end{array}$ \\
\hline
\end{tabular}

voluntariness to participate. Accordingly, 238 grade 12 science stream students constituted sample of the study.

Test items. The items were collected based on content of grade 12 mathematics syllabuses, minimum learning competency, and characteristic of conceptual knowledge assessment as suggested in the literature (for instance, Carlson, Oehrtman, \& Engelke, 2010). The test consists of five multiple choice items and two workout items. Each multiple choice item has two parts; to choose the correct answer from the given five alternatives and to give justification for the choice of an alternative. The distracters are designed to inform specific form of knowledge about a concept. For instance, in item 1, none of the first four alternatives are correct and they indicate specific form of conception about limit at a point. Table 1 presents this item and the corresponding interpretation of the distracters.

A pilot test of the items was conducted with students in a private school in the study area. 58 students participated in the pilot study. The aim of the pilot tests was to get feedback about the items before they were used in the study. Accordingly, necessary amendments were made based on the feedback collected from the pilot study.

\section{Data Analysis}

The analysis of the test result was captured using categories: correct, incorrect and no response. Then, for each item the respondents' errors were identified by looking for the wrong choice and analysis of reasons or wrong working and analysis of errors from the scripts. Since these errors or wrong answers constitute ways of difficulties and origins of difficulties that respondents have, the data were read over and over again to get an overall picture about existing difficulties and their ways of thinking and reasoning via the theoretical framework. This has also assisted by grouping and pattern coding of responses to get frequency that shows prevalence of a certain difficulty or strength. The work done is influenced by the stated theoretical framework, the method of analyzing students succession on a performance task "analysis of reasons" and "analysis of errors" as described in Messick (1988, p.87) and the literature. The literature documented that students' performance indicate correct answer for wrong reasons and wrong answer with high confidence (Luneta \& Makonye, 2010; Çetin, 2009; Juter, 2006). This is also witnessed in the pilot test. Thus, in the analysis attention was given to triangulation among items in a particular test script.

\section{RESULT AND DISCUSSION}

On the closed ended items, the choice of each distracter has an implication on students' concept image and level of conceptual knowledge. Each of these concept images that students possess is discussed in more detail below. Table 2 is summary of response for the first 5 items.

Referring to Table 2, 69 (29.0\%) of the students got the correct answer choice E for item 1 . While 160 (67.2\%) did not get the correct choice, the remaining 9 (3.8\%) left the item unanswered. Options A to D, are distracters that have potential to reveal existence of immature conceptual structure or conflicting concept images in limit of functions.

Accordingly, the percentage of choice A to D suggests that:

- $12(5 \%)$ of respondents think that limit is a boundary,

- $67(28.2 \%)$ of respondents think that limit is not attainable, 
Table 2. Breakdown of students' choices to the five items

\begin{tabular}{|c|c|c|c|c|c|c|c|c|c|c|c|c|}
\hline \multirow{3}{*}{ Item } & \multicolumn{10}{|c|}{ Frequency, $\mathrm{N}=238$} & \multirow{2}{*}{\multicolumn{2}{|c|}{ Non- respondents }} \\
\hline & \multicolumn{2}{|c|}{$\mathbf{A}$} & \multicolumn{2}{|c|}{$\mathbf{B}$} & \multicolumn{2}{|c|}{$\mathbf{C}$} & \multicolumn{2}{|c|}{ D } & \multicolumn{2}{|c|}{$\mathbf{E}$} & & \\
\hline & $\mathbf{N}$ & $\%$ & $\mathbf{N}$ & $\%$ & $\mathbf{N}$ & $\%$ & $\mathbf{N}$ & $\%$ & $\mathbf{N}$ & $\%$ & $\mathbf{N}$ & $\%$ \\
\hline 1 & 12 & 5.0 & 67 & 28.2 & 32 & 13.4 & 49 & 20.6 & $69 *$ & 29.0 & 9 & 3.8 \\
\hline 2 & 22 & 9.2 & 29 & 12.2 & 19 & 8.0 & $67 *$ & 28.2 & 98 & 41.2 & 3 & 1.2 \\
\hline 3 & 10 & 4.2 & 71 & 29.8 & 37 & 15.5 & 45 & 18.9 & $69 *$ & 29.0 & 6 & 2.5 \\
\hline 4 & 47 & 19.7 & 110 & 46.2 & 8 & 3.4 & $59^{*}$ & 24.8 & 3 & 1.2 & 11 & 4.6 \\
\hline 5 & 28 & 11.8 & $73^{*}$ & 30.7 & 62 & 26.0 & 27 & 11.3 & 34 & 14.3 & 14 & 5.9 \\
\hline
\end{tabular}

* correct answer of the item

\begin{tabular}{|c|c|}
\hline $\mathrm{S}_{16}$ & 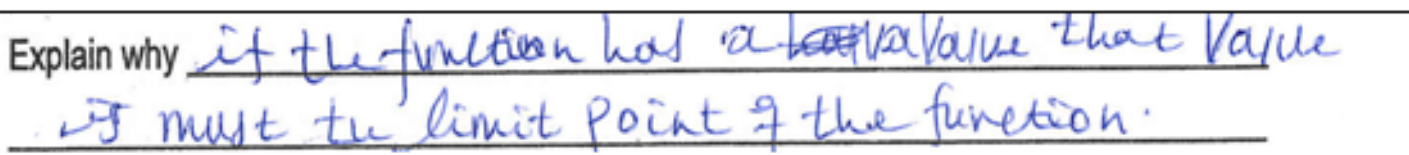 \\
\hline $\mathrm{S}_{03}$ & 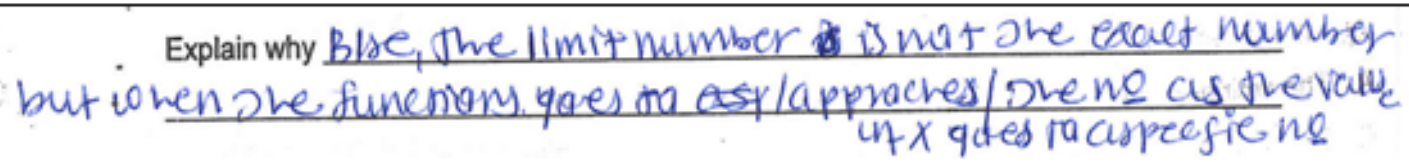 \\
\hline
\end{tabular}

Figure 2. Students' reasons to their choice of options in item 1

\begin{tabular}{|l|l|}
\hline $\mathrm{S}_{06}$ & Explain why Because, as the name indicates limit is to \\
& sas that approch of a number \\
\hline $\mathrm{S}_{14}$ & $\begin{array}{l}\text { Explain why Because limits doesn't guve exact vame but gives the } \\
\text { vaue appmach to thene. }\end{array}$ \\
\hline
\end{tabular}

Figure 3. Extracts showing limit as approximation concept image

- 32 (13.4\%) of respondents think that limit is an approximation (for instance, S03 as in Figure 1), and

- $49(20.6 \%)$ of respondents think that limit at a point is the same as value of the function at the limit point (for instance, $\mathrm{S}_{16}$ as in Figure 2).

Two major sources of these difficulties are clear from students' explanations. One is common language interference and the other is the way limit is introduced (Jaffar \& Dindyal, 2011; Tall, 1993). When introduction of limit was dominated by rational functions, where the zero of the denominator is the limit point (this approach is usually preferred to demonstrate the difference between function value and limit value), students in turn develop that limit is not attainable, but rather an approximation. Figure 3 is additional explanations on the issue which suggest how the difficulty is persistent.

Referring to Table 2, only 67 (28.2\%) respondents recognized the dual nature of limit and got the correct answer choice D for item 2. While $22(9.2 \%)$ think that limit is all about an infinite process, $29(12.2 \%)$ think that it has a finite value and has nothing to do with infinite process. 19 (8.0\%) of participants confirmed that limit is necessarily a boundary. In this item, option $\mathrm{E}$ has the largest response rate. This has many implications on the diversity of students' difficulties. To begin with, this misconception originates from the conception that every function is monotonic. The other is that being monotonic is a necessary condition for convergence. Most students in this group think that limit means boundary i.e. least upper bound if the function is increasing and the greatest lower bound if the function is decreasing. Since these values are unique (provided the function is monotonic), the limit is also unique or finite value. Figure 4 confirms that limit is a boundary concept image. 


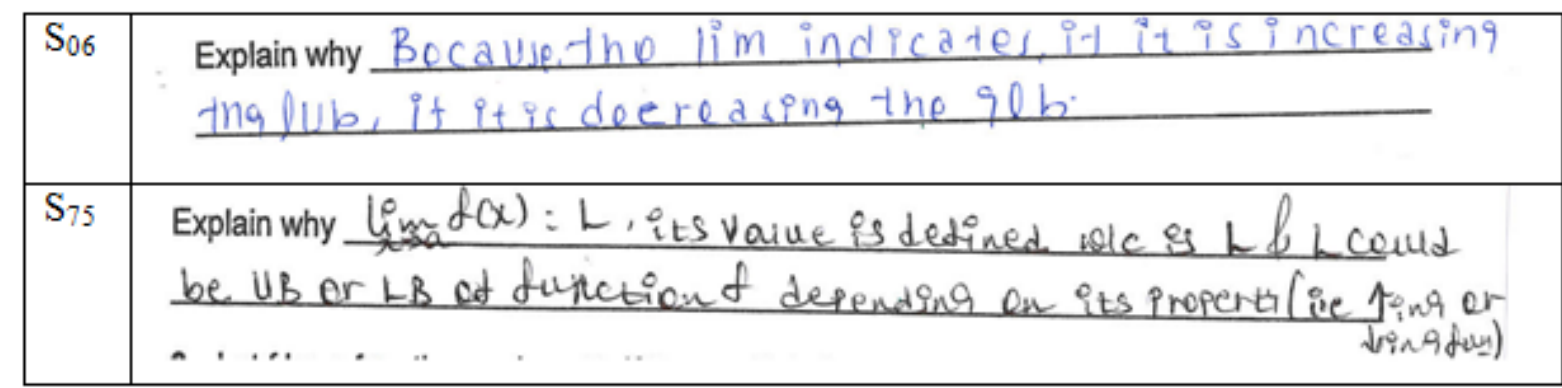

Figure 4. Extracts which shows limit is a boundary concept image

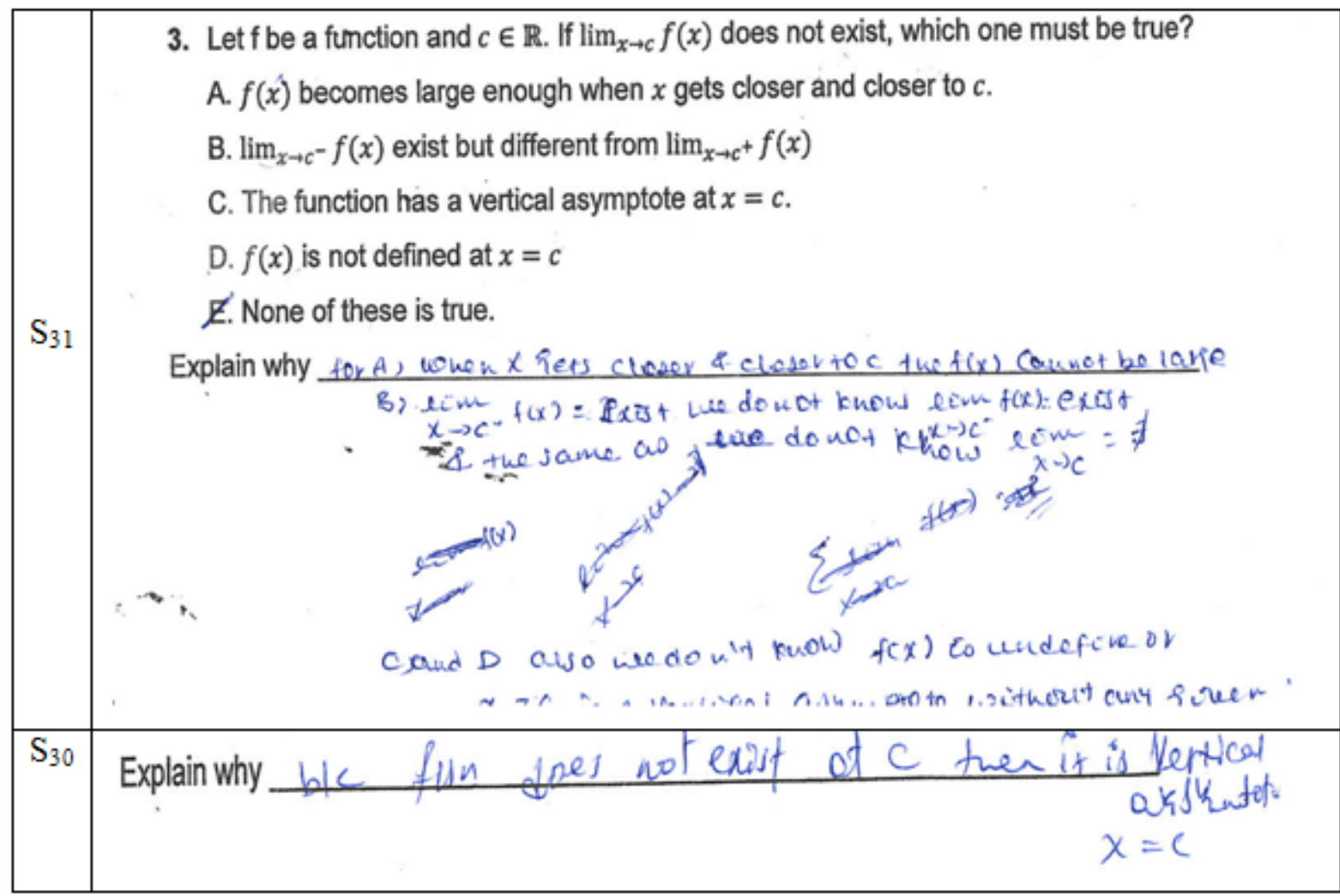

Figure 5. Extracts from correct and wrong answers on item 3

The aim of item 3 is to diagnose students' qualitative reasoning ability and consistency of reasoning on non-existence of limit at a point. Referring to the data in Table 2, only 69 (29.0\%) of them have clear symbolic interpretation ability as far as their response to this item is concerned. While 163 (68.5\%) of them have one or the other form of difficulty, 6 (2.5\%) of them left the item unanswered. In this item, options A to D, are distracters which demonstrate lack of knowledge on limit of functions. The percentage of choice A to D suggests that:

- $10(4.2 \%)$ think that limit does not exist necessarily imply that the function is unbounded,

- $71(29.8 \%)$ think that a function will have no limit only if the two side limit have different values,

- $37(15.5 \%)$ think that if $\lim _{x \rightarrow c} f(x)$ does not exist, then the graph of $f$ should have a vertical asymptote at $x=c$ (for instance, $\mathrm{S}_{30}$ as in Figure 5),

- 45 (18.9\%) confused existence of limit and being defined.

Figure 5 displays correct answer with correct reason $\left(\mathrm{S}_{31}\right)$ and wrong answer for wrong reason $\left(\mathrm{S}_{30}\right)$ on item 3. 


\begin{tabular}{|c|c|}
\hline $\mathrm{S}_{97}$ & 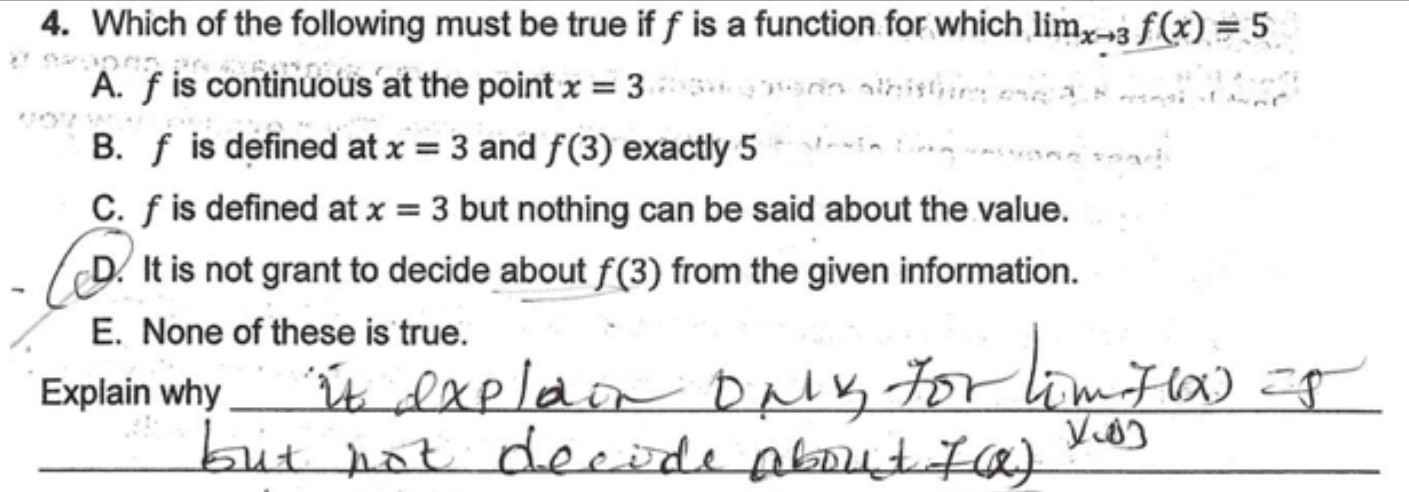 \\
\hline $\mathrm{S}_{42}$ & Explain why ble tionlt know the given cruestion. \\
\hline $\mathrm{S}_{102}$ & Explain why $R$. If we sor that $\lim _{x \rightarrow 3} f(x)=5, \lim _{x 3^{+}} f \frac{x}{=} \lim _{x \rightarrow 3^{-}} f(x)=\lim _{x \rightarrow 3}=5$ \\
\hline $\mathrm{S}_{74}$ & 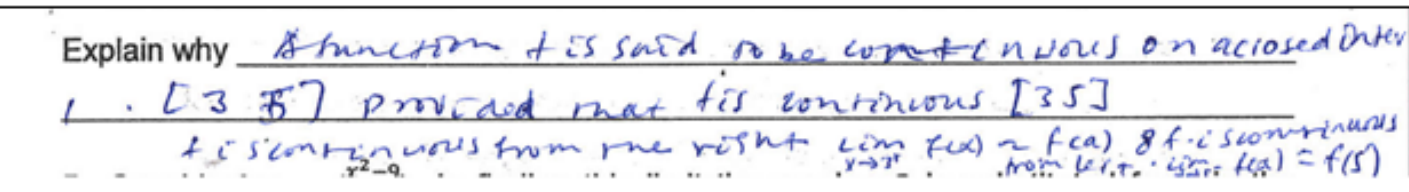 \\
\hline
\end{tabular}

Figure 6. Extracts of strong and weak reasons for item 4

Item 4 is aimed at examining students' knowledge on the relationship between limit and function value and limit and continuity interplay. Regarding this, the data in Table 2 revealed that while 59 (24.8\%) got the correct choice D, 168 (70.6\%) selected the other options and the remaining 11 (4.6\%) refused to answer the item. Only a small number of students gave a satisfactory explanation and showed strong knowledge of this concept. Others got the correct option but didn't support their choice of option with explanation. Accordingly, the percentages of choice A to $\mathrm{C}$ suggest that:

- 47 (19.7\%) think that existence of limit is sufficient for continuity of a function at a point,

- $110(46.2 \%)$ think that limit at a point is the same as the function value at the limit point and existence of limit is a sufficient for being defined,

- $8(3.4 \%)$ think that existence of limit is sufficient for being defined but nothing can be said about the function value based on the limit value.

In this item, option B has the highest respondent rate. The implication is that many students either do not differentiate limit value from function value or their experience is limited to continuous functions. Figure 6 disclose both strong $\left(\mathrm{S}_{97} \& \mathrm{~S}_{42}\right)$ and weak $\left(\mathrm{S}_{102} \& \mathrm{~S}_{74}\right)$ concept image for the interplay between function value and limit value.

The aim of item 5 is to establish students' linguistic issue in limit. It also reveals more about students' algebraic manipulation skills. All options, except B, are distracters which were arrived at due to linguistic ambiguity on the limit of functions. Accordingly, 73 (30.7\%) of them got the correct answer and 151 (63.4\%) missed it. The remaining 14 (5.9\%) left it unanswered and this is the highest non-response rate among all the five closed ended items. This may have its own implication on how the terms are confusing. The percentage of respondents on these incorrect options suggests that $28(11.8 \%)$ think that limit at a point is a substitution and if that substitution results indeterminate form the conclusion is that limit does not exist, 62 (26\%) think that $\frac{0}{0}=0,27(11.3 \%)$ think the indeterminate form $\frac{0}{0}$ is the same as undefined, and $34(14.3 \%)$ think the indeterminate form $\frac{0}{0}$ imply that the limit is infinity. Besides, students have incorrect interpretation of symbolic notations. Figure 7 displays how some of them incorrectly interpreted one side limit notation. 


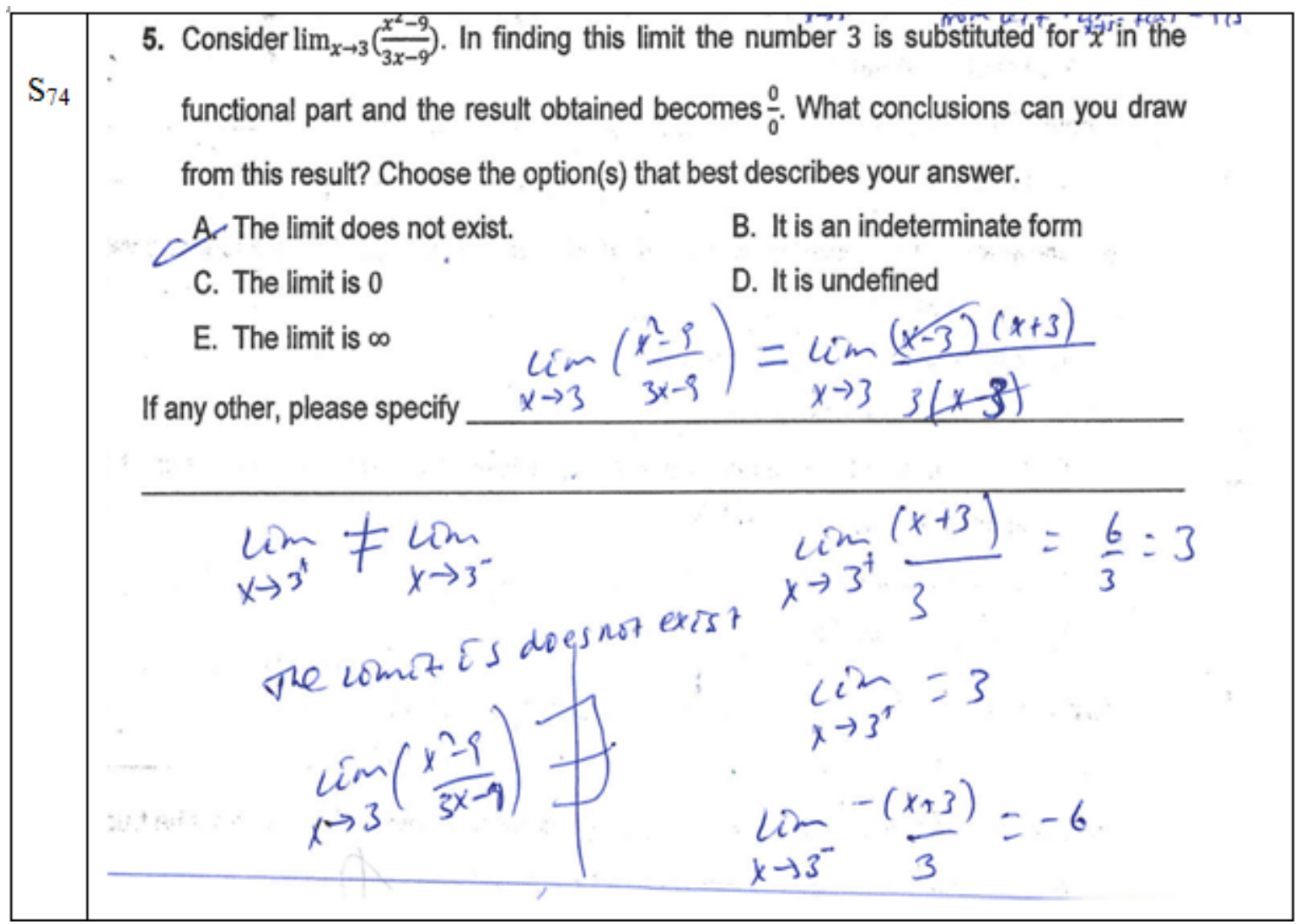

Figure 7. An extract displaying wrong interpretation of symbolic notation

Table 3. Breakdown of students' response to item 6

\begin{tabular}{cccccccc}
\hline & \multicolumn{7}{c}{ Frequency, $\mathbf{N = 2 3 8}$} \\
\hline \multicolumn{2}{c}{ Correct } & \multicolumn{2}{c}{ Incorrect } & \multicolumn{2}{c}{ Incomplete } & \multicolumn{2}{c}{ Non- respondent } \\
\hline $\mathbf{N}$ & $\mathbf{\%}$ & $\mathbf{N}$ & $\mathbf{\%}$ & $\mathbf{N}$ & $\mathbf{\%}$ & $\mathbf{N}$ & $\%$ \\
\hline 69 & 28.9 & 84 & 35.5 & 45 & 18.9 & 40 & 16.5 \\
\hline
\end{tabular}

The open ended items (item $6 \&$ 7) are designed to diagnose students' specific difficulties in limit at infinity, limit of a rational function, and to explore how they extend their knowledge on limit to a real life problem. In particular, item 6 helps to establish students' concept image of infinity and knowledge of coordination of processes. Students' response to this item is summarized as in Table 3.

According to the data in Table 3, 40 (16.5\%) students did not provide any answer to the item. While 69 (28.9\%) of them described it correctly (of course, only the algebraic part but not the interpretation), 84 (35.5\%) of them gave complete and meaning full procedure but incorrect conclusion whereas the remaining 45 (19\%) started the procedure but interrupted without a meaningful conclusion. Only $5 \%$ of them try to interpret the calculated result. Some difficulties observed in the incorrect responses were summarized as follows - wrong interpretation of limit rules, confusing limit and other concepts in calculus, treating infinity as a number, and errors in symbolic manipulation. Figure 8 is an extract that shows varies form of difficulties from two students test script. 


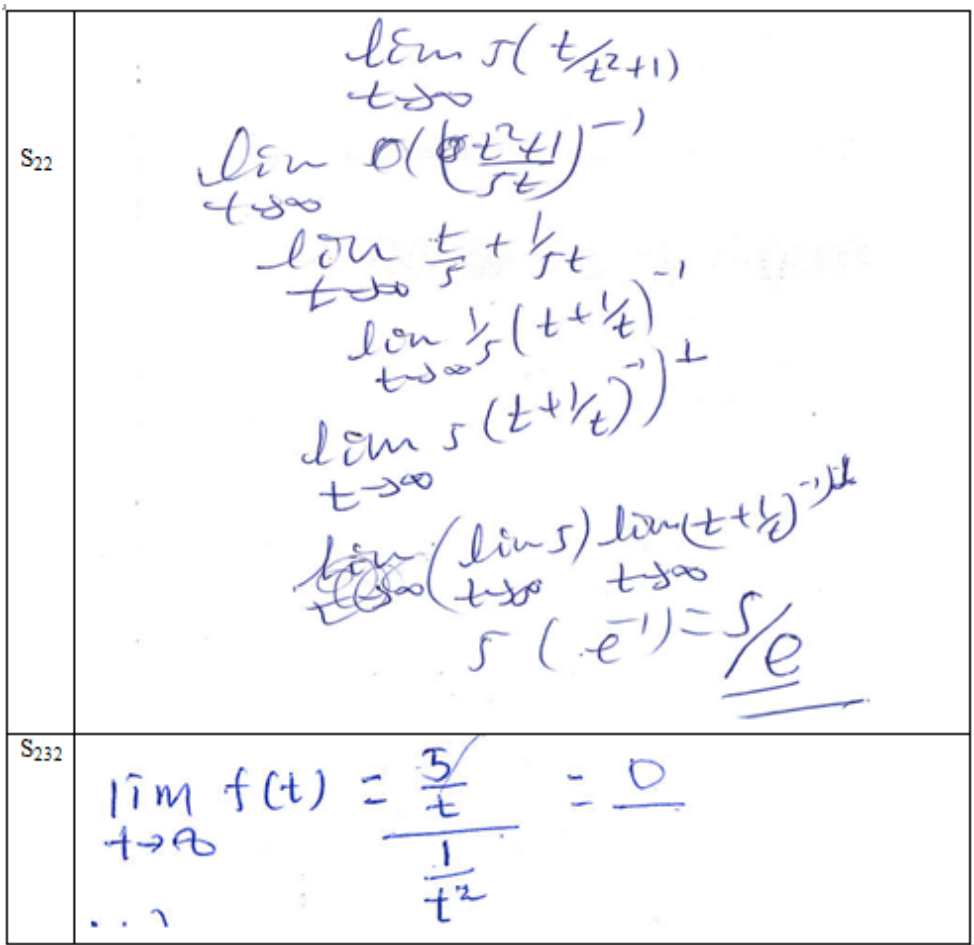

Figure 8. An extract which revealed wrong working of limit

Table 4. Breakdown of students' choices to item 7

\begin{tabular}{ccccccc}
\hline \multirow{2}{*}{ Sub-items } & \multicolumn{7}{c}{ Frequency, N=238 } \\
\cline { 2 - 7 } & \multicolumn{2}{c}{ Correct } & \multicolumn{2}{c}{ Incorrect } & Non- respondent \\
\cline { 2 - 7 } & $\mathbf{N}$ & $\mathbf{\%}$ & $\mathbf{N}$ & $\mathbf{\%}$ & $\mathbf{N}$ & 14.8 \\
\hline $7 \mathrm{a}$ & 118 & 49.5 & 85 & 35.7 & 35 & 12.6 \\
\hline $7 \mathrm{~b}^{2}$ & 57 & 24.0 & 31 & 13.0 & 30 & 17.2 \\
\hline $7 \mathrm{c}$ & 95 & 39.9 & 102 & 42.8 & 41 & . \\
\hline
\end{tabular}

Table 5. Reasons behind the incorrect response to item 7c

\begin{tabular}{|c|c|c|c|}
\hline No. & Response & Frequency & Reason \\
\hline 1 & 11 & 24 & $\begin{array}{l}\text { ignore the restriction on the domain after simplification i.e. they } \\
\qquad \text { consider } \frac{2 x^{2}-x-15}{x-3}=2 x+5, \forall \mathrm{x}\end{array}$ \\
\hline 2 & 0 & 19 & Most of them think that $\frac{0}{0}=0$ \\
\hline 3 & 3 & 9 & as in 1 above and manipulation errors (simplify \\
\hline 4 & 1 & 4 & $\underline{2 x^{2}-x-15}$ as $2 x-5$, as $(x-3)(x-5)$, as $\left.x+\frac{5}{)}\right)$ \\
\hline 5 & -1 & 3 & $-5), \operatorname{as} x+\frac{-}{2}$ \\
\hline 6 & $\infty$ & 6 & think that $\frac{0}{0}=\infty$ \\
\hline 7 & $\begin{array}{l}\text { others }(9,45 \\
\left.4.5, \frac{0}{0}\right)\end{array}$ & 37 & different reasons \\
\hline
\end{tabular}

In item $7 \mathrm{a}, 118(49.5 \%)$ of them correctly answered that the functions limit exists at $\mathrm{x}=3$, but only 57 $(24.0 \%)$ of them computed the correct limit value in $7 \mathrm{~b}$. Many students missed the result due to an algebraic manipulation error and knowledge of indeterminate forms. With regard to 7c, while 95 (39.9\%) of them correctly said that the function has no value at $x=3,102(42.8 \%)$ said the function has value. The remaining $41(17.2 \%)$ said nothing about the function value. While Table 4 summarizes students' response to items 7 , Table 5 is summary of the incorrect function values and reasons behind these incorrect conclusions.

2 based on correct respondents of $7 \mathrm{a}$ 


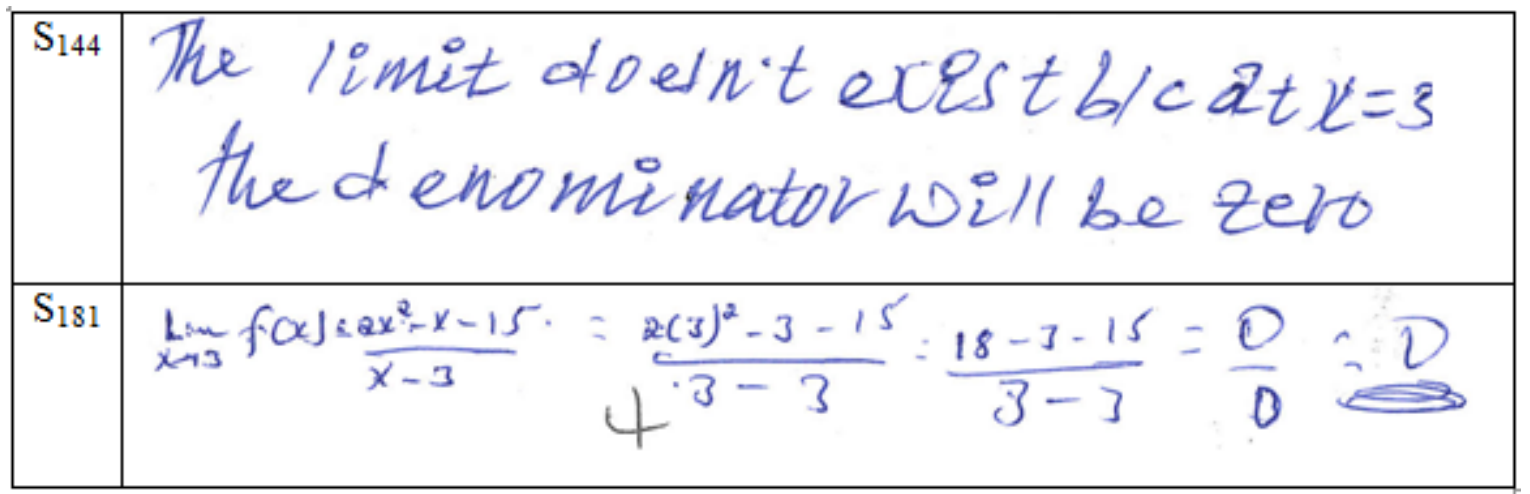

Figure 9. An extract of limited knowledge in limit

Figure 9 is evidence of students' limited knowledge of limit. As in $\mathrm{S}_{144}$ performance of limit is influenced by the concept image that limit is a substitution and as in $\mathrm{S}_{181}$ not only by the concept image that limit is a substitution but also the concept of the indeterminate form.

In general, students' performance in the test items revealed that many students' knowledge on limit is inadequate and basically suitable for continuous functions. In particular, many students are influence by an arithmetic approach for items demanding an algebraic approach (for instance, in item 7, 11.7\% students evaluate the function just at $x=3$ instead of simplifying the rational expression). This practice of "point-bypoint or static way" of evaluating independent variable of a function is termed as "action view of function" (Carlson et al., 2010) and this action view of function than process view is the main challenge to progress in calculus (Maharaj, 2013).

Most students (as observed in item 6), have an actual value image of infinity than potential. But the potential infinity conception has to do more to compute limit at infinity. According to Jones (2015, p. 108), "potential infinity is more in line with a process, so valuable to limit at infinity $\left(\lim _{x \rightarrow \infty} f(x)\right)$ but actual infinity has more in common with an object" so valuable for infinite limit.

Students also exhibit algebraic manipulation errors and face additional challenge to compute limit of rational function at the zero of the denominator. Different types of algebraic manipulation errors, which emanate from pre-calculus algebra (like, simplifying $\frac{2 x^{2}-x-15}{x-3}=2 x+5, \forall \mathrm{x}$ or $\frac{2 x^{2}-x-15}{x-3}$ as $2 \mathrm{x}-5$, as $(\mathrm{x}-3)(\mathrm{x}-$ 5) as $x+\frac{5}{2}$ ) were observed. The literature (Siyepu, 2015; Maharaj, 2010; Pillay, 2008; Juter, 2006; Jordaan, 2005), has also documented that most students' gap in computational abilities or algebraic manipulation skill from pre-calculus algebra limits their performance in calculus. According to Siyepu (2015, p.15), these difficulties root from focuses of prior learning i.e. "prior learning subject to surface learning of familiar exercises". Besides, some students lack proper handling of symbolic notation (for instance, $\lim _{x \rightarrow 3^{+}}=3$, or $\lim _{\mathrm{t} \rightarrow \infty}=\frac{5}{\infty}=0$ ), which display their knowledge is based on symbolic manipulations that do not give attention to imbedded concepts.

It is common to see misinterpretation of the indeterminate form (Evaluate, $\frac{0}{0}=0$, or $\frac{0}{0}=\infty$ ). This agrees with the findings in the literature (Jaffar \& Dindyal, 2011; Jordaan, 2005; Moru, 2006). The literature has found that most students are not aware when to use these terms. In limit, the term "infinity" will be used to express being unbounded and "does not exist" will be used to mean that the one sided limits are different. However, the literature revealed that students do not have such mental image. According to Jaffar and Dindyal (2011), these difficulties rooted from the introduction of operations on real numbers. These misinterpretations together action views of function are main sources of difficulties in particular to limit of rational functions. As students test scripts revealed, after substitution when they get the indeterminate form $\frac{0}{0}$, they conclude that either the limit is zero or the limit does not exist.

Within the linguistic issue, concept images: limit is a boundary, limit is never attainable, and limit is an approximation was observed. In particular limit is a boundary and limit does not exist necessarily imply that the function is unbounded were noticed from students' qualitative description. In addition, most students have no coherence and consistency in their work and have conflicting concept images about limit. They have a restricted concept image of limit of functions, as a result their concept image of limit falls into either all about 
an infinite process and nothing to do with finite value or limit is all about a finite value and nothing to do with infinite process. Only $28.2 \%$ of participants recognize dual nature of limit i.e. limit involves an infinite process and has a finite value, provided it exists.

One distinction between advanced mathematics and elementary mathematics is the role of definition in advanced mathematics (Tall, 2002). When introducing a new concept, an ordinary starting point is through a definition. This demands relating terms in a mathematical language and terms in the medium of instruction. The terms 'approach to', 'tend to', 'reach', and 'converge' are frequently used to define or describe limit. These are not only terms with a technical and formal definition in mathematics, but also have everyday uses not connected to their mathematical meanings (Fernandez-Plaza, Rico \& Ruiz-Hidalgo, 2013). Several researchers confirmed that due to the conflicts between formal and colloquial uses of these terms, students face challenge to accurately express the mathematical meaning of the concept of limit (Jaffar \& Dindyal, 2011; Moru, 2006). Thus, cognitive structures of the limit of a function formed by the students contained a lot of inconsistency and is often stumped (Jordaan, 2005; Moru, 2006). It is also confirmed that students provide correct answers for wrong reasons. For instance, students may compute limit of a continuous function using an overgeneralization that limit is the same as function value. That is why some researchers suggest qualitative analysis of students reasoning to examine true nature of students' knowledge. The literature documented that students' performance indicate correct answer for wrong reasons and wrong answer with high confidence (Çetin, 2009; Juter, 2006; Luneta \& Makonye, 2010).

Most students over generalize that limit at a point is a substitution, if $\lim _{x \rightarrow c} f(x)$ does not exist, then the graph of $f$ should have a vertical asymptote at $\mathrm{x}=\mathrm{c}$, a function will have no limit only if when the two side limit have different values. Most of these over generalizations rooted from introduction of limit (Tall, 1993). When introduction of limit was dominated by continuous functions, students in turn develop that limit is nothing but the same as the function's value at the limit point. Besides, it is common to see that students evaluate a function " $f$ " at the first few points (usually, integers) close to "a" to compute $\lim _{x \rightarrow a} f(x)$. This discrete and sequential thinking of variables (as integers) than real number domain of functions corresponds to "action view of function" (Carlson et al., 2010). But, calculus learning demand beyond action level conception. According to APOS theory, computing values of the function " $\mathrm{f}$ " at a finitely many successive discrete points should be followed by the action of: interiorization of these actions to establish a domain process in which the input values approaches "a" and the subsequent outputs values approaches the limit value "L" (Moru, 2006).

Most students can compute limit of a function but they face a challenge to attach a meaning to the calculated value. For instance, in item 6 , only $5 \%$ of participants have interpreted the results obtained from algebraic computation. Of course some students also fail to demonstrate correct symbolic manipulation, misinterpret limit rules and indeterminate forms, and treat infinity as a number. The literature documented that all the teaching, learning and textbooks approach contribute a share to students' difficulties in problem solving as their focus is largely on manipulation of symbolic aspect on routine exercises (Bezuidenhout, 2001; Rabadi, 2015).

\section{CONCLUSION}

Generally, the findings reveal that most students lack conceptual knowledge. Even those, who are leveled as average in their performance, are good at symbolic manipulation and their knowledge is dominated by procedure manipulation. Some students, who are leveled as active, these are not more than $3.8 \%$ of all the participants, demonstrate: large example space, express continuity in terms of limit, show consistent concept image, interiorize actions into processes, construct coordinated processes; and encapsulate processes into objects, have problem solving framework and have coherent framework of reasoning.

Observed difficulties are categorized in to themes as follows: Static view of dynamic process, lack of describing relationship of terms, over generalization and inconsistent cognitive structure, over dependence on procedural learning, lack of making logical connection between conceptual aspects, lack of coherent and flexibility of reasoning, and lack of procedural fluency and wrong interpretation of symbolic notations. Ways of thinking and approaches that caused these difficulties are also synthesized as: arithmetic thinking rather than algebraic, linguistic ambiguity, compartmentalized learning, dependence on concept image than concept definition, obtain correct answers for wrong reasons, and focuses on lower level cognitive demanding exercises.

Hence, we recommend that mathematics teachers who teach calculus for beginners should concern about the necessary pedagogical-content knowledge. They are also advised to be aware about current literature on 
students' difficulties. Moreover, teachers have to provide activities (both for the class presentation and assessment) that gives an opportunity to students on: dual nature of thinking, qualitative and subjective description as part of response to items, focus on quality of knowledge, conceptual learning, open problem solving, making skill and concept parallel, and expose them to unfamiliar and non-routine type problems. On the other hand, the classroom environment should have to be reform oriented that can be characterized by: student centered, effective communication, constructive approach, involving real life and reasoning level problems, students should be allowed to explore and verbalize their mathematical ideas. We also recommend that local educational authority need to assist the teaching-learning process by way of providing need-based training to mathematics teachers.

\section{Disclosure statement}

No potential conflict of interest was reported by the authors.

\section{Notes on contributors}

Ashebir Sidelil Sebsibe - Wachem University, Department of Mathematics, Hossana, Ethiopia.

Nosisi Nellie Feza - Central University of Technology, Faculty of Humanities, Free State (CUT), Private Bag X20539, Bloemfontein, 9300, South Africa.

\section{REFERENCES}

Asiala, M., Brown, A., DeVries, D. J., Dubinsky, E., Mathews, D., \& Thomas, K. (1997). A framework for research and curriculum development in undergraduate mathematics education. Retrieved from https://www.researchgate.net

Aspinwall, L., \& Miller, L. D. (2001). Diagnosing conflict factors in calculus through students' writings: One teacher's reflections. The Journal of Mathematical Behavior, 20(1), 89-107. https://doi.org/10.1016/S0732-3123(01)00063-3

Berry, J. S., \& Nyman, M. A. (2003). Promoting students' graphical understanding of the calculus. The Journal of Mathematical Behavior, 22(4), 481-497. https://doi.org/10.1016/j.jmathb.2003.09.006

Bezuidenhout, J. (2001). Limits and continuity: Some conceptions of first-year students. International Journal of Mathematical Education in Science and Technology, 32(4), 487-500. https://doi.org/10.1080/00207390010022590

Carlson, M., \& Oehrtman, M. (2005). Key aspects of knowing and learning the concept of function. Mathematical Association of America Research Sampler, (9). Retrieved from https://www.maa.org

Carlson, M., Oehrtman, M., \& Engelke, N. (2010). The precalculus concept assessment: A tool for assessing students' reasoning abilities and understandings. Cognition and Instruction, 28(2), 113-145. https://doi.org/10.1080/07370001003676587

Çetin, I. (2009). Students' understanding of limit concept: An APOS perspective (Doctoral dissertation), Middle East Technical University. Retrieved from https://etd.lib.metu.edu.tr

Cottrill, J., Dubinsky, E., Nichols, D., Schwingendorf, K., Thomas, K., \& Vidakovic, D. (1996). Understanding the limit concept: beginning with a coordinated process scheme. Journal of Mathematical Behavior, 15(2), 167-192. https://doi.org/10.1016/S0732-3123(96)90015-2

Dubinsky, E. (2002). Reflective abstraction in advanced mathematical thinking. In D. Tall (Ed.), Advanced mathematical thinking (11 ${ }^{\text {th }}$ ed., pp. 95-123). London: Kluwer Academic Publisher. https://doi.org/10.1007/0-306-47203-1_7

Dubinsky, E., \& McDonald, M. A. (2001). APOS: A constructivist theory of learning in undergraduate mathematics education research. In The teaching and learning of mathematics at university level (pp. 275-282). Springer, Dordrecht. https://doi.org/10.1007/0-306-47231-7_25

Fernández-Plaza, J. A., Rico, L., \& Ruiz-Hidalgo, J. F. (2013). Concept of finite limit of a function at a point: Meanings and specific terms. International Journal of Mathematical Education in Science and Technology, 44(5), 699-710. https://doi.org/10.1080/0020739X.2013.805887

Glasersfeld, V. E. (1995). Radical constructivism: A way of learning and knowing. London: The Falmer Press. 
Idris, N. (2009). Enhancing students' understanding in calculus trough writing. International Electronic Journal of Mathematics Education, 4(1), 36-55.

Jaffar, S., \& Dindyal, J. (2011). Language-related misconceptions in the study of limits. Mathematics: Traditions and [New] Practices, 390-397. Retrieved from https://www.merga.net.au

Jones, S. R. (2015). Calculus limits involving infinity: the role of students' informal dynamic reasoning. International Journal of Mathematical Education in Science and Technology, 46(1), 105-126 https://doi.org/10.1080/0020739X.2014.941427

Jordaan, T. (2005). Misconceptions of the limit concept in a mathematics course for engineering students (Master's thesis), University of South Africa. Retrieved from http://uir.unisa.ac.za

Juter, K. (2006). Limits of functions-students solving tasks. Australian Senior Mathematics Journal, 20(1), 15-30. Retrieved from UNISA e-journal Database: Education Source

Luneta, K., \& Makonye, P. J. (2010). Learner errors and misconceptions in elementary analysis: A case study of a grade 12 class in South Africa. Acta Didactica Napocensia, 3(3), 35-46.

Maharaj, A. (2010). An APOS analysis of students' understanding of the concept of a limit of a function. Pythagoras, 71, 41-52. https://doi.org/10.4102/pythagoras.v0i71.6

Maharaj, A. (2013). An APOS analysis of natural science students' understanding of derivatives. South African Journal of Education, 33(1), 1-19. https://doi.org/10.15700/saje.v33n1a458

Makonye, J. P. (2012). Learner errors on calculus tasks in the NSC examinations: Towards an analytical protocol for learner perturbable concepts in introductory differentiation. International Journal of Learning, 18(6), 339-357. https://doi.org/10.18848/1447-9494/CGP/v18i06/47634

Messick, S. (1988). Validity. In R. L. Linn (Ed.), Educational measurement (3 ${ }^{\text {rd }}$ ed. pp. 13-104). New York: Macmillan.

Moru, E. K. (2006). Epistemological obstacles in coming to understand the limit concept at undergraduate level: a case of the National University of Lesotho (Doctoral dissertation), University of the Western Cape. Retrieved from http://etd.uwc.ac.za

Muzangwa, J., \& Chifamba, P. (2012). Analysis of Errors and Misconceptions in the Learning of Calculus by Undergraduate Students. Educational Studies in Mathematics, 80(3), 389-412. https://doi.org/10.1007/s10649-011-9357-7

Pillay, E. (2008). Grade twelve learners' understanding of the concept of derivative (Masters dissertation), University of KwaZulu-Natal. Retrieved from https://researchspace.ukzn.ac.za

Pritchard, A., \& Woollard, J. (2010). Psychology for the Classroom: Constructivism and Social Learning. New York: Routledge.

Rabadi, N. (2015). Overcoming difficulties and misconceptions in calculus (Doctoral dissertation, Teachers College, Columbia University). Available from ProQuest dissertations and theses. (UMI 3683397).

Roble, D. B. (2017). Communicating and valuing students' productive struggle and creativity in calculus. Turkish Online Journal of Design Art and Communication, 7(2), 255-263. https://doi.org/10.7456/10702100/009

Sadler, P. M., \& Sonnert, G. (2017). Factors influencing success in introductory college calculus. The role of calculus in the transition from high school to college mathematics. Retrieved from https://www.maa.org

Salas, S., Hille, E., \& Etgen, G. (2007). Calculus: one and several variables (10 th ed.). United States of America: John Wiley \& Sons, Inc.

Siyepu, S. W. (2015). Analysis of errors in derivatives of trigonometric functions. International Journal of STEM Education, 2(1), 1-16. https://doi.org/10.1186/s40594-015-0029-5

Stewart, S. (2008). Understanding linear algebra concepts through the embodied, symbolic and formal worlds of mathematical thinking (Doctoral dissertation), The University of Auckland. Retrieved from https://researchspace.auckland.ac.nz

Tall, D. (1993). Students' difficulties in calculus. Proceedings of Working Group 3 on Students' Difficulties in Calculus, (August 1992), 3, 13-28.

Tall, D. (2002). The psychology of advanced mathematical thinking. In D. Tall (Ed.), Advanced Mathematical thinking (11 ${ }^{\text {th }}$ ed., pp. 3-21). London: Kluwer academic publisher. https://doi.org/10.1007/0-306-472031_1 
Tall, D., \& Vinner, S. (1981). Concept image and concept definition in mathematics with particular reference to limits and continuity. Educational studies in Mathematics, 12(2), 151-169. https://doi.org/10.1007/BF00305619

Zollman, A. (2014). University students' limited knowledge of limits from calculus through differential equations. The mathematics education for the future project: Proceedings of the 12th International Conference, (pp. 693-698). Retrieved from https://www.researchgate.net 